\title{
LABA/LAMA combinations versus LAMA monotherapy or LABA/ICS in COPD: a systematic review and meta-analysis
}

This article was published in the following Dove Press journal:

International Journal of COPD

17 March 2017

Number of times this article has been viewed

\author{
Gustavo J Rodrigo' \\ David Price ${ }^{2,3}$ \\ Antonio Anzueto 4,5 \\ Dave Singh ${ }^{6}$ \\ Pablo Altman ${ }^{7}$ \\ Giovanni Bader ${ }^{8}$ \\ Francesco Patalano ${ }^{8}$ \\ Robert Fogel ${ }^{7}$ \\ Konstantinos Kostikas ${ }^{8}$ \\ 'Departamento de Emergencia, \\ Hospital Central de las Fuerzas \\ Armadas, Montevideo, Uruguay; \\ ${ }^{2}$ Academic Primary Care, Division of \\ Applied Health Sciences, University \\ of Aberdeen, Aberdeen, Scotland, \\ UK; ${ }^{3}$ Observational and Pragmatic \\ Research Institute, Singapore; \\ ${ }^{4}$ University of Texas Health Science \\ Center, ${ }^{5}$ South Texas Veterans Health \\ Care System, San Antonio, TX, USA; \\ ${ }^{6}$ Medicines Evaluation Unit, National \\ Institute for Health Research \\ Respiratory and Allergy Clinical \\ Research Facility, University Hospital \\ of South Manchester NHS Foundation \\ Trust, University of Manchester, \\ Manchester, England, UK; ${ }^{7}$ Novartis \\ Pharmaceuticals Corporation, East \\ Hanover, NJ, USA; ${ }^{8}$ Novartis Pharma \\ AG, Basel, Switzerland
}

Correspondence: Gustavo J Rodrigo Departamento de Emergencia, Hospital Central de las Fuerzas Armadas, Avenue 8 de Octubre 3020, Montevideo

11300 , Uruguay

Tel +59893834050

Email gustavo.javier.rodrigo@gmail.com
Background: Randomized controlled trials (RCTs) indicate that long-acting bronchodilator combinations, such as $\beta_{2}$-agonist (LABA)/muscarinic antagonist (LAMA), have favorable efficacy compared with commonly used COPD treatments. The objective of this analysis was to compare the efficacy and safety of LABA/LAMA with LAMA or LABA/inhaled corticosteroid (ICS) in adults with stable moderate-to-very-severe COPD.

Methods: This systematic review and meta-analysis (PubMed/MEDLINE, Embase, Cochrane Library and clinical trial/manufacturer databases) included RCTs comparing $\geq 12$ weeks' LABA/ LAMA treatment with LAMA and/or LABA/ICS (approved doses only). Eligible studies were independently selected by two authors using predefined data fields; the Preferred Reporting Items for Systematic Reviews and Meta-Analyses guidelines were followed.

Results: Eighteen studies (23 trials) were eligible ( $\mathrm{N}=20,185)$. LABA/LAMA significantly improved trough forced expiratory volume in 1 second $\left(\mathrm{FEV}_{1}\right)$ from baseline to week 12 versus both LAMA and LABA/ICS $(0.07 \mathrm{~L}$ and $0.08 \mathrm{~L}, P<0.0001)$, with patients more likely to achieve clinically important improvements in $\mathrm{FEV}_{1}$ of $>100 \mathrm{~mL}$ (risk ratio [RR]: 1.33, 95\% confidence interval [CI]: $[1.20,1.46]$ and RR: $1.44,95 \% \mathrm{CI}$ : [1.33, 1.56], respectively, the number needed to treat being eight and six, respectively). LABA/LAMA improved transitional dyspnea index and St George's Respiratory Questionnaire scores at week 12 versus LAMA (both $P<0.0001$ ), but not versus LABA/ICS, and reduced rescue medication use versus both $(P<0.0001$ and $P=0.001$, respectively). LABA/LAMA significantly reduced moderate/severe exacerbation rate compared with LABA/ICS (RR 0.82, 95\% CI: [0.75, 0.91]). Adverse event (AE) incidence was no different for LABA/LAMA versus LAMA treatment, but it was lower versus LABA/ICS (RR 0.94, 95\% CI: $[0.89,0.99]$ ), including a lower pneumonia risk (RR 0.59, 95\% CI: [0.43, 0.81]). LABA/LAMA presented a lower risk for withdrawals due to lack of efficacy versus LAMA (RR: $0.66,95 \% \mathrm{CI}$ : $[0.51,0.87])$ and due to AEs versus LABA/ICS (RR: 0.83, 95\% CI: [0.69, 0.99]).

Conclusion: The greater efficacy and comparable safety profiles observed with LABA/LAMA combinations versus LAMA or LABA/ICS support their potential role as first-line treatment options in COPD. These findings are of direct relevance to clinical practice because we included all currently available LABA/LAMAs and comparators, only at doses approved for clinical use. Keywords: LABA/LAMA combinations, COPD, LAMA, LABA/ICS, meta-analysis

\section{Introduction}

Long-acting bronchodilators, whether $\beta_{2}$ agonists (LABAs) or muscarinic antagonists (LAMAs), are central to symptom management in patients with COPD. ${ }^{1}$ As well as improving lung function and health-related quality of life (HRQoL), they help prevent exacerbations and increase exercise endurance by reducing pulmonary hyperinflation 
and dyspnea. ${ }^{2}$ LABA/inhaled corticosteroid (ICS) combinations are indicated for patients with severe-to-very-severe COPD and a history of repeated exacerbations. Despite these indications, however, LABA/ICS combinations remain the second-most commonly prescribed first-line treatments (after LAMA monotherapy) across the range of COPD severities. ${ }^{3,4}$ The use of LABA/ICS combinations has been associated with a decrease in the rate of COPD exacerbations but with an increased risk of pneumonia. ${ }^{5}$

LAMAs and LABAs achieve bronchodilation through different mechanisms: muscarinic antagonists block acetylcholine-mediated bronchoconstriction by binding to $M_{3}$ receptors in airway smooth muscle, ${ }^{6}$ whereas $\beta_{2}$ agonists induce smooth muscle relaxation by stimulating $\beta_{2}$-adrenergic receptors. ${ }^{7,8}$ These distinct mechanisms result in differences in observed efficacy between the two classes of bronchodilators. Hence, some data suggest that LABAs are more effective at improving symptoms and HRQoL than LAMAs, while LAMAs are superior to LABAs in reducing exacerbations, with the differential efficacy likely occurring through modes of action beyond bronchodilation. ${ }^{8-12}$ Such differences provide the opportunity of combining LABAs and LAMAs in an attempt to improve treatment outcomes.

Accumulating evidence from randomized controlled trials (RCTs) has shown that LABA/LAMA fixed-dose combinations (FDCs) have beneficial effects on lung function and patient-reported outcomes compared with LAMA or LABA/ICS treatments, while demonstrating a similar safety profile. ${ }^{13-15}$ In a recent network meta-analysis, LABA/LAMA combinations have also been shown to be more effective than either of the monotherapy component in improving lung function, QoL, symptom scores and exacerbation rates while maintaining similar safety profiles. ${ }^{16}$ Building on this, the aim of this meta-analysis was to compare the pooled efficacy and safety data from trials of FDCs of LABA/LAMAs with the two most commonly prescribed first-line treatments: LAMAs and LABA/ICS combinations.

\section{Materials and methods}

\section{Literature search and terms used}

Preferred Reporting Items for Systematic Reviews and MetaAnalyses (PRISMA) guidelines were used to perform this systematic review. ${ }^{17}$ Full details are provided in the online Supplementary materials.

\section{Inclusion criteria and outcome assessments}

Randomized, parallel-group, controlled design of $>4$ weeks' duration, which compared LABA/LAMA FDCs with
LAMA monotherapy or LABA/ICS combinations, were included. The studies were to have been conducted in adult patients aged $\geq 40$ years with stable, moderate-to-very severe COPD. ${ }^{1}$

Study treatments were restricted to all currently available LABA/LAMA combinations at the approved doses of these combinations and their comparators (in the US or EU; Table S1).

Studies were required to report at least one of the following outcomes: trough and/or peak $\mathrm{FEV}_{1}$; transitional dyspnea index (TDI) total score; St George's Respiratory Questionnaire (SGRQ) total score; rescue medication use (puffs/day); COPD exacerbations (as a study end point); safety (frequency of adverse events [AEs], serious AEs [SAEs] and cardiovascular events); pneumonia incidence; withdrawal from treatment (due to AEs or lack of efficacy); or deaths while on treatment.

The primary outcome was trough $\mathrm{FEV}_{1}$; secondary outcomes included peak FEV ${ }_{1}$, TDI, SGRQ, rescue medication use, prospectively collected annualized rate of COPD exacerbations, AEs and related safety measures. The effect of treatments was established at weeks 12, 24 or 26 , and 52 (dependent on the trial) for efficacy end points, as well as throughout the trial duration for safety outcomes. In addition, in studies in which the data were evaluated, the proportions of patients who achieved minimal clinically important differences (MCIDs) in FEV ${ }_{1}$, TDI and SGRQ have also been presented; these are defined as a $>100 \mathrm{~mL}$ increase over baseline for $\mathrm{FEV}_{1},{ }^{18} \mathrm{a} \geq 1$ unit increase in $\mathrm{TDI},{ }^{19}$ and $\mathrm{a} \geq 4$ unit decrease in SGRQ score. ${ }^{20}$

\section{Data extraction and risk of bias}

\section{assessment}

Two authors (GJR and DP) reviewed the search results for relevant article titles meeting the inclusion criteria. The reviewers worked independently during study selection and data extraction; disagreements, if any, were resolved by discussion to obtain consensus.

Risk of bias of eligible trials was assessed by applying the Cochrane collaborations tool; ${ }^{21}$ further details are provided in the online Supplementary materials.

\section{Data analysis}

The meta-analysis was performed using Review Manager, version 5.3.5 (Copenhagen: The Nordic Cochrane Centre, The Cochrane Collaboration, 2014) as described in detail in the online Supplementary materials. In all analyses, the $P$-values were based on a two-tailed test with $P<0.05$ considered statistically significant. 
Outcomes were pooled as forest plots using mean differences (inverse variance [IV] or generic IV method), Mantel-Haenszel risk ratios (RRs) or risk differences (RDs). Precision of the estimates was quantified with 95\% confidence intervals (CIs), and heterogeneity was assessed using the $I^{2}$ test. ${ }^{22}$ Random-effects models were used to address variations across studies. ${ }^{23}$

\section{Results}

\section{Studies included in the analyses}

The study selection process is described in Figure 1, with further details supplied in the online Supplementary materials. Eighteen studies (comprising 23 clinical trials in total) fulfilled the eligibility criteria, and all were included in the analysis $(\mathrm{N}=20,185)$; both reviewers were in full agreement as to their inclusion. Details of the studies are summarized in Table 1; five comprised pooled data from two clinical trials. One of four pharmaceutical companies (AstraZeneca, Boehringer Ingelheim, GlaxoSmithKline and Novartis) sponsored each of the studies, all of which involved randomized comparisons of approved doses of COPD treatments or placebo. Twelve of the studies compared LABA/LAMA with LAMA,,$^{7,15,24-33}$ while six compared LABA/LAMA with LABA/ICS (salmeterol/fluticasone propionate); ${ }^{34-39}$ two of the trials $^{25,26}$ included two or more comparators. Further details for each of the studies can be found at https://ClinicalTrials. gov/ or in their respective primary publications. ${ }^{7,15,24-39}$

Most of the studies showed a low risk of bias in the six items of the Cochrane instrument ${ }^{21}$ (online Supplementary materials; Figures S1-S3).

\section{Effect of treatments on lung function (trough and peak $F E V_{1}$ )}

The overall treatment effect for each of the treatment comparisons are shown in Table 2 for each outcome measure at each of the protocol-defined time points. At week 12, significant increases from baseline were observed in trough $\mathrm{FEV}_{1}$ for the LABA/LAMAs indacaterol (Ind)/ glycopyrronium (Gly) (both dose regimens), umeclidinium (Umec)/vilanterol (Vi) and tiotropium (Tio)/olodaterol (Olo)

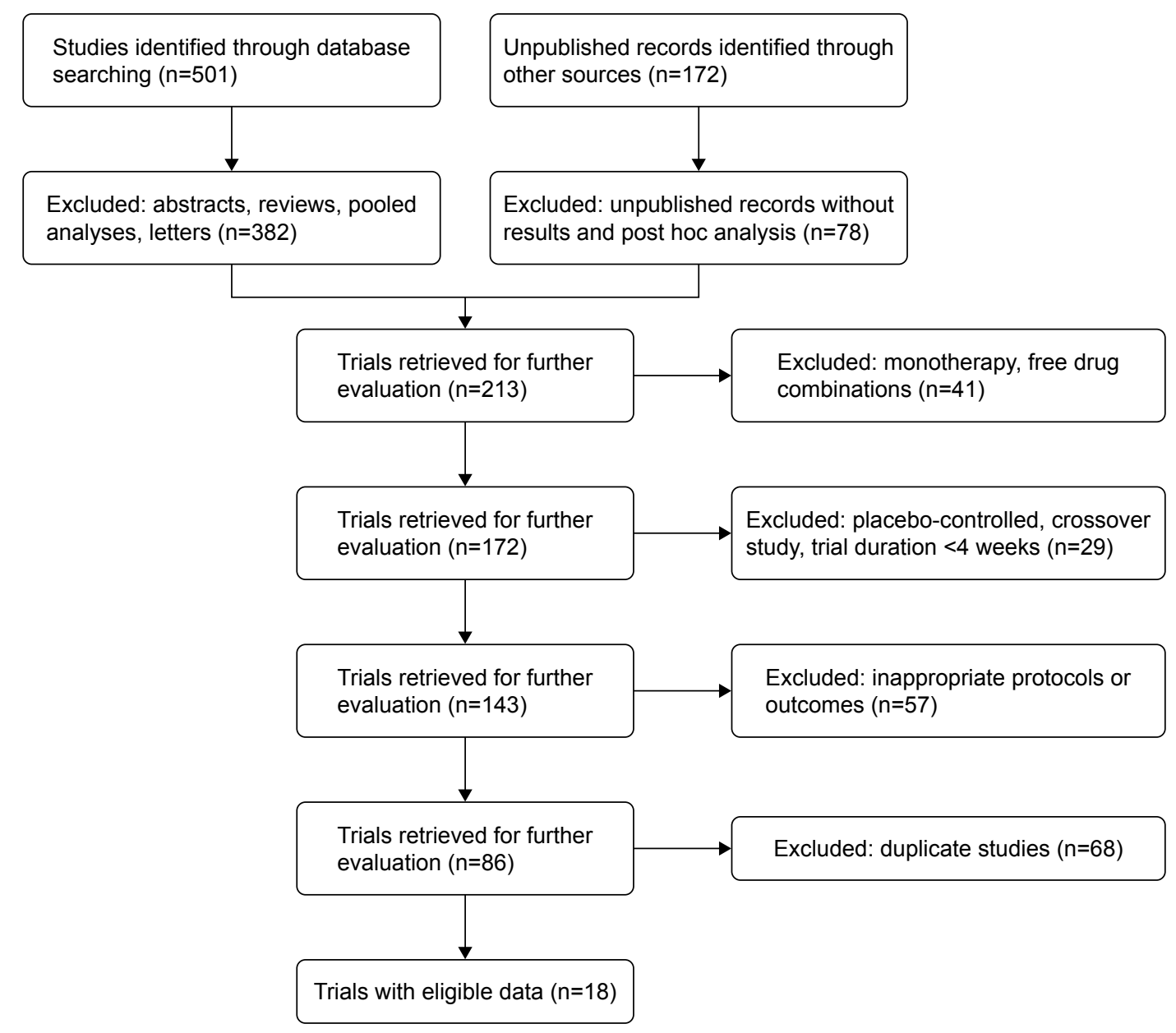

Figure I Study selection process: PRISMA flow diagram identifying studies included in the meta-analysis. 


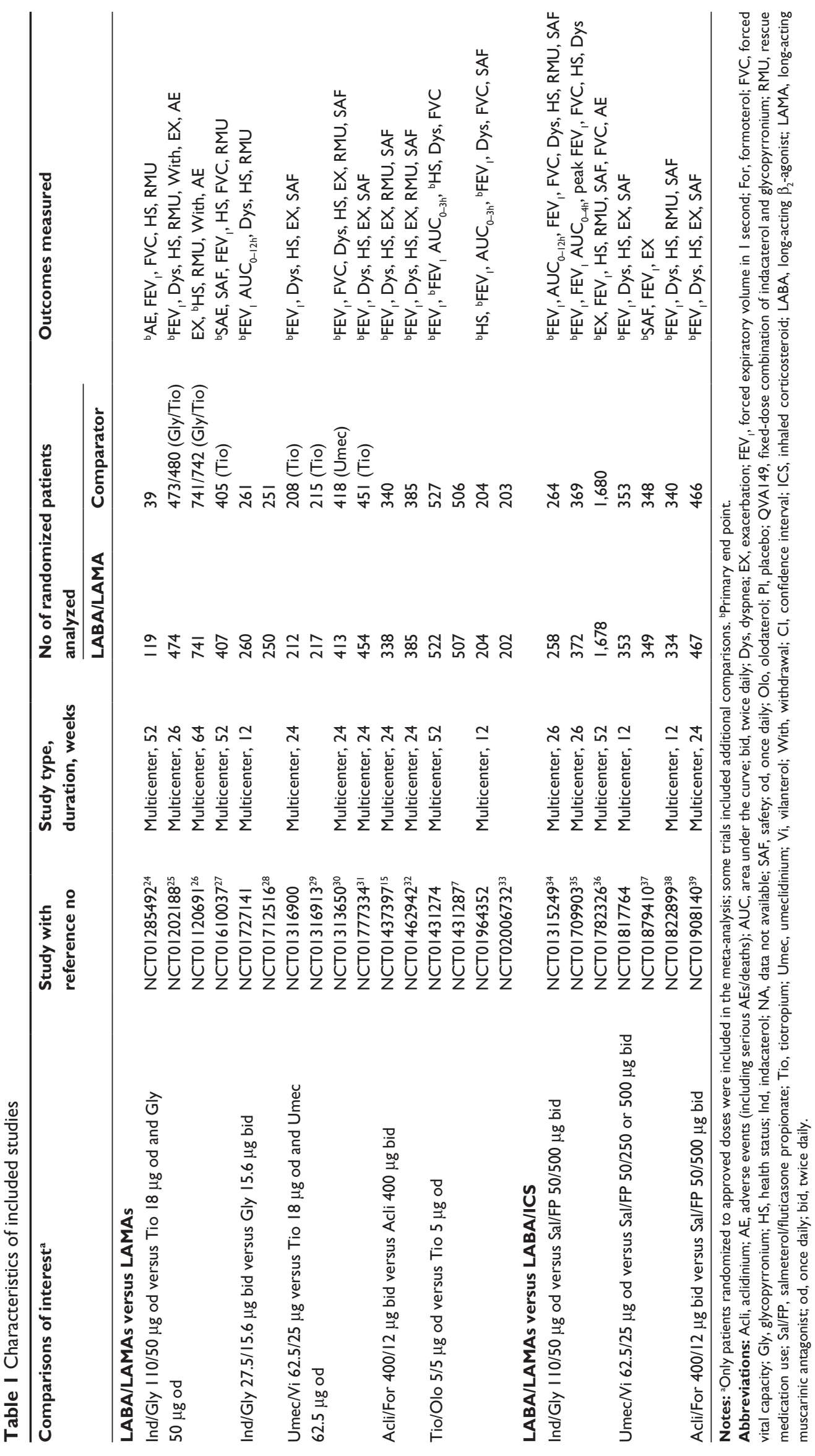


Table 2 Effect of LABA/LAMA versus LAMA or LABA/ICS on trough and peak FEV,

\begin{tabular}{|c|c|c|c|c|c|c|}
\hline \multirow[t]{2}{*}{ Outcome measure } & \multirow{2}{*}{$\begin{array}{l}\text { Studies } \\
\text { included }\end{array}$} & \multicolumn{2}{|l|}{ No of patients } & \multirow[t]{2}{*}{ Estimate } & \multirow[t]{2}{*}{ Effect $(95 \% \mathrm{Cl})$} & \multirow{2}{*}{$\begin{array}{l}I^{2}, \% \\
\text { (P-value) }\end{array}$} \\
\hline & & LABA/LAMA & Comparator & & & \\
\hline \multicolumn{7}{|c|}{ Trough FEV $(\mathrm{L})$ from baseline to } \\
\hline \multicolumn{7}{|c|}{ LABA/LAMA versus LAMA } \\
\hline Week 12 & $7,15,24-33$ & 5,565 & 6,615 & Mean difference & $0.07(0.05,0.09)$ & $91(<0.000$ I $)$ \\
\hline Week 24-26 & $15,24-33$ & 4,584 & 5,552 & & $0.07(0.05,0.08)$ & $56(<0.0001)$ \\
\hline Week 52 & $24,26,27,33$ & 2,015 & 2,488 & & $0.07(0.05,0.10)$ & $63(<0.0001)$ \\
\hline Total assessed for $M C I^{a}$ & $25,29-31$ & $\mathrm{I}, 765$ & 2,240 & Relative risk & $1.33(1.20,1.46)$ & $55(<0.000 \mathrm{I})$ \\
\hline Total with MCID & & 1,018 & 978 & NNTB & $8(6,9)$ & \\
\hline \multicolumn{7}{|c|}{ LABA/LAMA versus $L A B A / I C S$} \\
\hline Week 12 & $34-36,39$ & 3,142 & 3,123 & Mean difference & $0.08(0.07,0.09)$ & $0(<0.000 \mathrm{I})$ \\
\hline Week 24-26 & $34-38$ & 2,563 & 2,537 & & $0.06(0.00,0.12)$ & $90(0.04)$ \\
\hline Total assessed for MCID & $35,37,38$ & $|, 37|$ & I,383 & Relative risk & $1.44(1.33,1.56)$ & $0(<0.000 \mathrm{I})$ \\
\hline Total with MCID & & & & NNTB & $6(5,7)$ & \\
\hline \multirow{2}{*}{\multicolumn{7}{|c|}{$\begin{array}{c}\text { Peak FEV }(L) \text { from baseline to } \\
\text { LABA/LAMA versus LAMA }\end{array}$}} \\
\hline & & & & & & \\
\hline Week 12 & 28,32 & 893 & 868 & Mean difference & $0.10(0.08,0.12)$ & $0(<0.000$ I $)$ \\
\hline Week 24-26 & $25,29-32$ & 2,150 & 2,625 & & $0.11(0.09,0.12)$ & $0(<0.000 \mathrm{I})$ \\
\hline \multicolumn{7}{|c|}{ LABA/LAMA versus LABA/ICS } \\
\hline Week 12 & $34,35,37,38$ & I,552 & $\mathrm{I}, 544$ & Mean difference & $0.12(0.10,0.14)$ & $0(<0.000 \mathrm{I})$ \\
\hline Week 24-26 & $34,35,39$ & 953 & 932 & & $0.12(0.09,0.15)$ & $62(<0.000 \mathrm{I})$ \\
\hline
\end{tabular}

Note: ${ }^{\mathrm{M}} \mathrm{MCID} \geq 100 \mathrm{~mL}$ above baseline.

Abbreviations: $\mathrm{Cl}$, confidence interval; MCID, minimum clinically important difference; NNTB, number needed to treat for benefit; ICS, inhaled corticosteroid; LABA, long-acting $\beta_{2}$-agonist; LAMA, long-acting muscarinic antagonist; FEV , forced expiratory volume in I second; TDI, transitional dyspnea index.

relative to the respective LAMAs evaluated in their studies (mean differences: 0.06-0.10 L; $P<0.0001$; Figure 2). The between-treatment difference for aclidinium (Acli)/formoterol (For) versus Acli was not statistically significantly different $(P=0.06)$, but a trend in favor of Acli/For was evident.

Overall, for all LABA/LAMA versus LAMA comparisons, a significant improvement in trough $\mathrm{FEV}_{1}$ with $\mathrm{LABA} /$ LAMA treatment was observed at week 12 (mean overall difference: 0.07 L, 95\% confidence interval [CI]: [0.05, 0.09]; $P<0.0001$ relative to LAMA monotherapy). This improvement was maintained at weeks 24-26 and at week 52 (mean difference: 0.07 L, 95\% CI: [0.05, 0.08], and mean difference: 0.07 L, 95\% CI: [0.05, 0.10], respectively; both $P<0.0001$; Table 2; Figure S4). In addition, in studies where MCID was evaluated, 33\% more patients receiving LABA/LAMA rather than LAMA treatments achieved the MCID in trough $\mathrm{FEV}_{1}$ of $>100 \mathrm{~mL}$ above baseline (RR: 1.33; 95\% CI [1.20, 1.46]; Table 2). The number needed to treat to achieve this treatment benefit (NNTB) was 8 (95\% CI [6, 9]; Table 2). The absolute proportions of patients achieving any MCID were 58\% (1,018 of 1,765$)$ and $44 \%$ (978 of 2,240), respectively.

LABA/LAMA treatment also significantly increased trough $\mathrm{FEV}_{1}$ relative to $\mathrm{LABA} / \mathrm{ICS}$, both at the week 12 and week 24-26 time points (overall mean differences: 0.08 L, 95\% CI: [0.07, 0.09], $P<0.0001$; and 0.06 L, 95\% CI: $[0.00,0.12], P=0.04$, respectively; Figure 3; Table 2).
LABA/LAMA-treated patients had a 44\% greater likelihood of achieving an MCID in trough $\mathrm{FEV}_{1}$ than those receiving LABA/ICS (RR: 1.44; 95\% CI: [1.33, 1.56]; Table 2), with an NNTB of 6 at week 12 (95\% CI: [5, 7]; Table 2). The absolute proportions of patients achieving any MCID (where evaluated) were $59 \%$ (803 of 1,371) and $41 \%$ (562 of 1,383), respectively.

Peak $\mathrm{FEV}_{1}$ at week 12 and at weeks 24-26 was also higher in LABA/LAMA-treated patients versus both LAMAor LABA/ICS-treated patients (overall mean differences: 0.10-0.12 L; all $P<0.0001$; Table 2; Figure S5).

\section{Effect of treatments on dyspnea, health status and rescue medication use}

The effects of each treatment on dyspnea and health status (assessed by TDI and SGRQ, respectively), as well as rescue medication use, were determined at protocol-defined time points for individual trials and for treatment comparison subgroups. Overall treatment effects for all study subgroups combined are shown in Table 3.

TDI focal score was significantly improved in LABA/ LAMA- versus LAMA-treated patients at weeks 12 and 24 (mean difference: 0.5 points, 95\% CI: [0.32, 0.68], $P<0.0001$, and mean difference: 0.29 points, 95\% CI: $[0.12,0.46], P=0.0006$, respectively; Table 3; Figure S6A). Furthermore, in studies wherein it was evaluated, LABA/ 


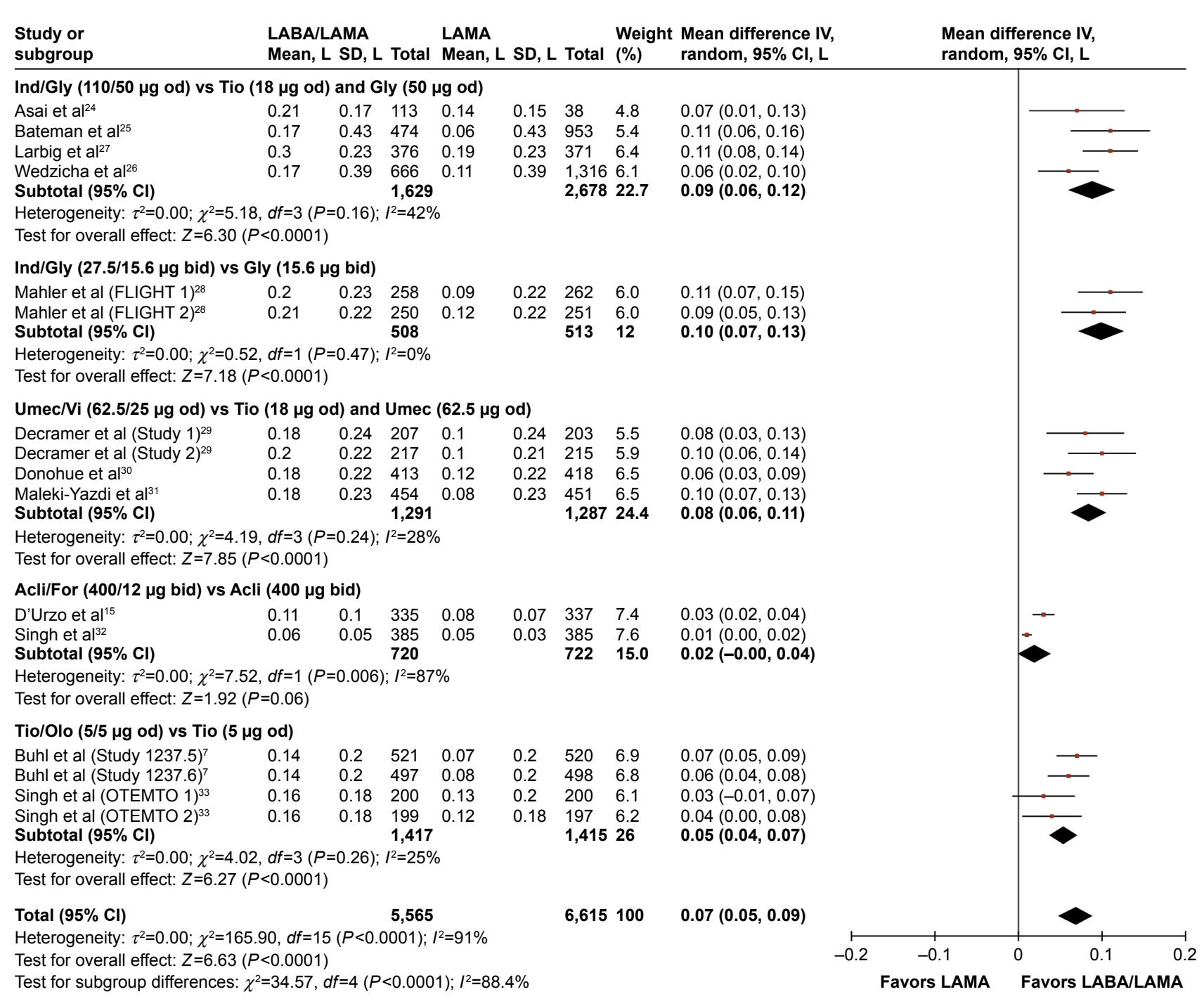

Figure 2 Pooled mean difference for trough FEV (change from baseline, L) at week 12, with 95\% Cls, for eligible studies comparing approved doses of LABA/LAMA combinations with approved LAMAs.

Abbreviations: $\mathrm{Cl}$, confidence interval; $\mathrm{FEV}$, forced expiratory volume in I second; LABA, long-acting $\beta_{2}$-agonist; LAMA, long-acting muscarinic antagonist; SD, standard deviation; IV, intravenous; od, once daily; bid, twice daily.

LAMA-treated patients were $12 \%$ more likely to achieve an MCID in TDI ( $\geq 1$ point increase) compared with LAMAtreated patients (RR: 1.12; 95\% CI: [1.06, 1.18]; Table 3), with an NNTB of 19 patients (95\% CI: [12, 36]). The absolute proportions of patients achieving any MCID were $61 \%(1,500$ of 2,444$)$ and $56 \%(1,604$ of 2,865$)$, respectively.

No statistically significant difference between LABA/ LAMA and LABA/ICS treatments with respect to TDI focal scores at weeks 12 and 26 were observed $(P=0.09$ and $P=0.29$, respectively; Table 3; Figure $\mathrm{S} 6 \mathrm{~B})$, although a trend in favor of LABA/LAMA treatment was observed.

With respect to the effect of different treatments on health status, SGRQ total scores (mean difference from baseline) at the week 12 and 24 time points were significantly improved in LABA/LAMA- versus LAMA-treated patients (mean difference: $-1.84,95 \% \mathrm{CI}$ : $[-2.31,-1.37]$, and mean difference: $-1.34,95 \% \mathrm{CI}$ : $[-1.94,-0.75]$ points, respectively, both $P<0.0001$; Table 3; Figure S7A [i] and [ii]). By week 52, the intertreatment difference was no longer statistically significant (mean difference: $-1.21,95 \% \mathrm{CI}$ : $[-2.64,0.21], P=0.09$; Table 3; Figure S7A [iii]), although the direction of the treatment benefit remained in favor of LABA/ LAMA treatment. Furthermore, SGRQ scores at week 52 were only captured in three studies, compared with 11 and 8 in the earlier time points; therefore, this finding may not be as robust as the earlier time points because the end point was tested in a comparatively smaller population. Heterogeneity between the three trials comprising the week 52 end point was also relatively high, at an $I^{2}$ of $58 \%$. In studies where MCID was evaluated, at the end of treatment, LABA/LAMA-treated 


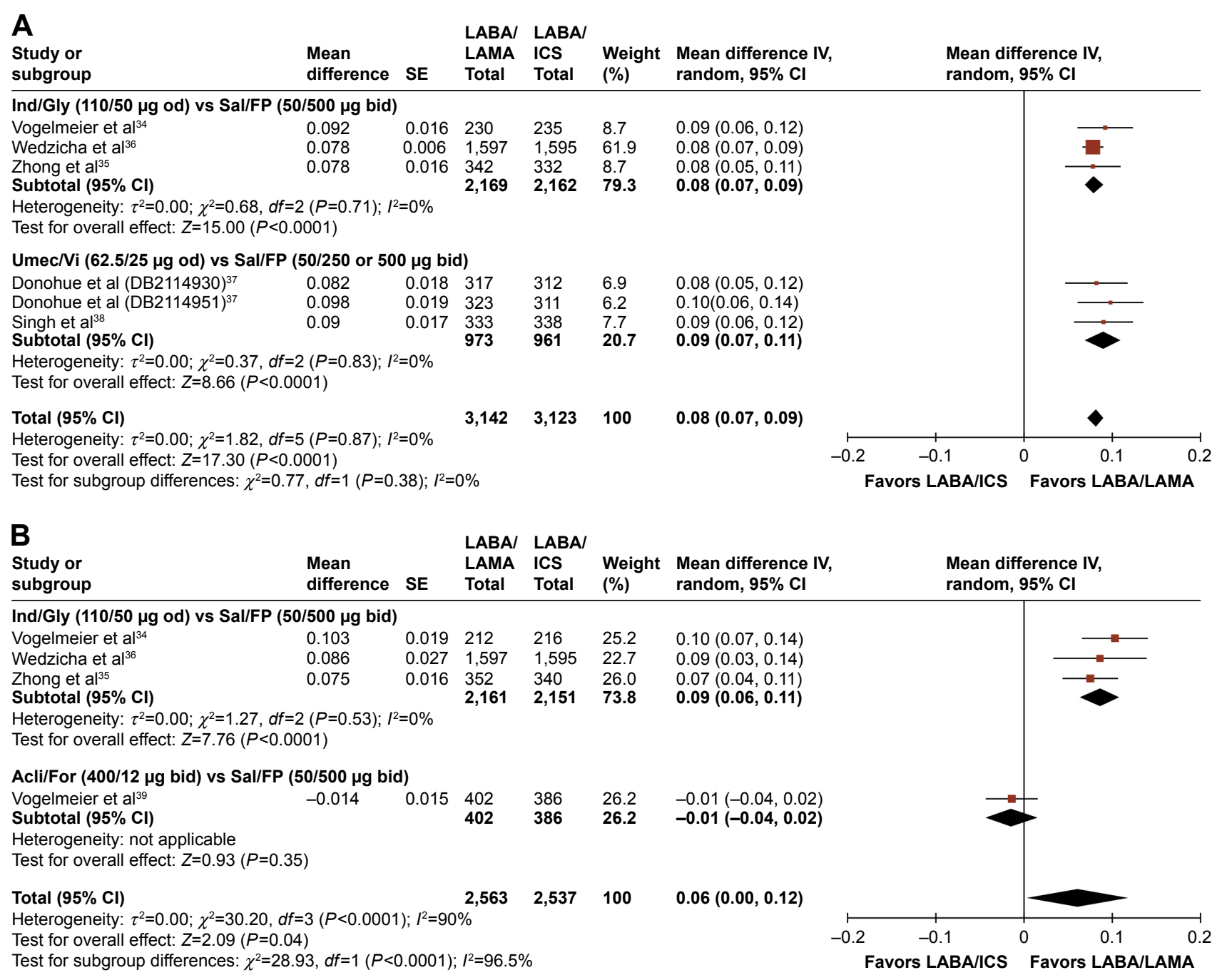

Figure 3 Pooled mean difference for trough FEV (change from baseline, L) at (A) week 12 and (B) weeks 24-26, with 95\% Cls, for eligible studies comparing approved LABA/LAMA combinations with approved LABA/ICS combinations.

Abbreviations: $\mathrm{Cl}$, confidence interval; $\mathrm{FEV}_{1}$, forced expiratory volume in I second; LABA, long-acting $\beta_{2}$-agonist; LAMA, long-acting muscarinic antagonist; $\mathrm{SE}$, standard error; od, once daily; bid, twice daily; FP, fluticasone propionate.

patients were found to be $14 \%$ more likely to have achieved an MCID in SGRQ ( $\geq 4$ unit decrease) than LAMA-treated patients (RR: 1.14, 95\% CI: [1.09, 1.20]); the NNTB was 16 (95\% CI: $[12,22])$ (Table 3). The absolute proportions of patients achieving any MCID were 56\% (2,493 of 4,450) and $50 \%(2,668$ of 5,385$)$, respectively.

Overall, no statistically significant difference was observed between LABA/LAMA and LABA/ICS treatments with respect to SGRQ total score at week 12 (mean difference: $-0.43,95 \%$ CI: $[-1.28,0.42], P=0.32)$, potentially driven by the considerable heterogeneity between the trials, providing an overall $I^{2}$ of $48 \%$. At week 26, SGRQ scores had significantly improved in LABA/LAMA- versus LABA/ICS-treated patients (mean difference: $-1.13,95 \%$ CI: $[-1.78,-0.48], P=0.0006$; Table 3; Figure S7B), an effect driven by the data of the Ind/Gly data available at that time point. Interestingly, the trial that contributed the greatest weight to the analysis of this comparison, FLAME, ${ }^{36}$ was highly significantly in favor of LABA/LAMA at both time points (Figure S7B).

At the end of treatment, rescue medication use relative to baseline use was significantly reduced in LABA/ LAMA-treated patients compared with those treated with either LAMA or LABA/ICS (reduction of -0.58 puffs/day, 95\% CI: $[-0.70,-0.45] ; P<0.0001$; and -0.18 puffs/day, 95\% CI: $[-0.28,-0.07], P=0.001$, respectively) (Table 3 ; Figure $\mathrm{S} 8$ ).

\section{Effect of treatments on COPD exacerbations and hospitalizations}

There were insufficient data to conduct a meta-analysis on the effect of treatment on prospectively collected COPD 


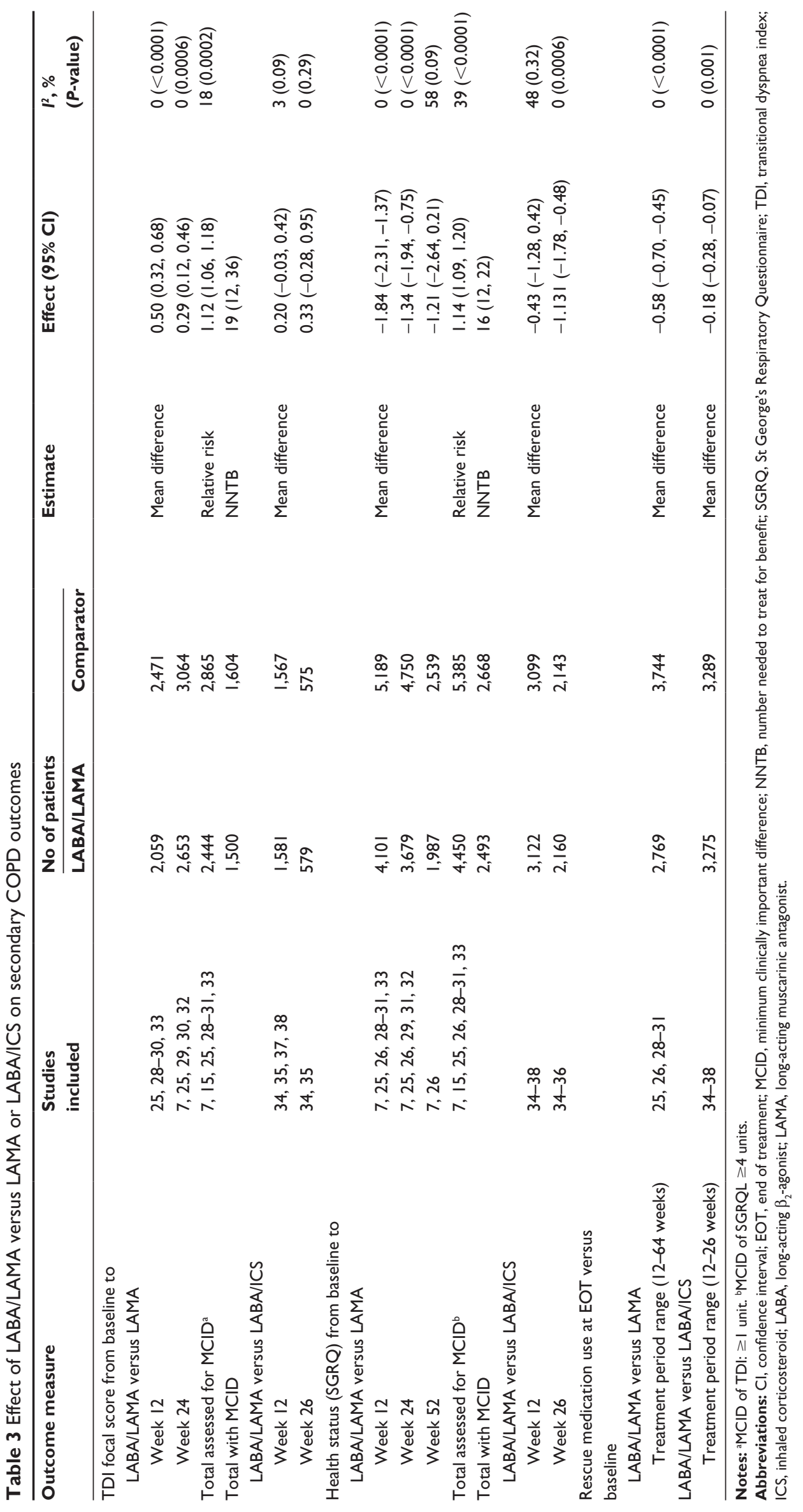


exacerbation rates in LABA/LAMA- versus LAMA-treated patients because such data were available in only one study. ${ }^{26}$ However, compared with LABA/ICS treatment, LABA/ LAMA significantly reduced the annualized rate of moderate and/or severe exacerbations (RR: 0.82, 95\% CI: [0.75, 0.91]; $P<0.001$; Figure 4A). A trend in favor of LABA/LAMA was also observed for severe exacerbations alone, with one study $^{35}$ revealing a significant benefit in favor of LABA/ LAMA, and another ${ }^{36}$ showing a numerical benefit. However, heterogeneity between the two studies was high for this end point, at $I^{2}=74 \%$ (Figure $4 \mathrm{~B}$ ).

\section{Effect of treatments on safety outcomes}

The relative effects of each COPD treatment class on the safety end points of $\mathrm{AE}$ and $\mathrm{SAE}$ incidence, numbers of withdrawals (due to AEs or lack of efficacy) and deaths, as well as the effect of treatment on annualized exacerbation rate, are presented in Table 4.

No significant difference in the incidence of AEs was observed in patients treated with LABA/LAMA combinations versus those on LAMA monotherapy (RR: 1.00, 95\% CI: [0.98, 1.02], $P=0.95$; Table 4; Figure 5A). Likewise, no significant difference in the incidence of SAEs (RR: 1.01, 95\% CI: $[0.88,1.15], P=0.94)$ nor in the incidence of pneumonia or cardiovascular-related events (RR: $1.04,95 \% \mathrm{CI}$ : [0.78, 1.38], $P=0.79$, and RR: $1.09,95 \%$ CI: $[0.77,1.55], P=0.62$, respectively; Figures S9A, S10 and S11A) was observed.

Compared with LABA/ICS treatment, however, LABA/ LAMA-treated patients had significantly lower AE rates (RR: $0.94,95 \%$ CI: [0.89, 0.99], $P=0.02$ ), with a number needed to treat for harm $(\mathrm{NNTH})$ of $32(95 \% \mathrm{CI}: 18,100)$ (Table 4; Figure 5B). There were significantly fewer incidences of pneumonia in the LABA/LAMA treatment arm versus the LABA/ICS treatment arm (RR: 0.59, 95\% CI: [0.43, 0.81], $P=0.001)$, with an NNTH of 84 (95\% CI: 54, 184) (Table 4; Figure 6). Neither the incidence of SAEs nor cardiovascularrelated events were significantly different between the LABA/LAMA and LABA/ICS groups (RR: 0.90, 95\% CI: [0.74, 1.10], $P=0.32$, and RR: $1.17,95 \% \mathrm{CI}:[0.78,1.76]$, $P=0.45$, respectively; Figures S9B and $\underline{\mathrm{S} 11 \mathrm{~B}}$ ).

The overall rates of death were low across treatment groups, with no significant differences observed between patients treated with LABA/LAMA and those on either LAMA or LABA/ICS ( $P=0.46$ and 0.65 , respectively; Table 4; Figure S12).

The rate of withdrawal from treatment due to AEs was significantly lower in LABA/LAMA-treated patients compared with those treated with LABA/ICS (RR: 0.83, 95\% CI: [0.69, 0.99], $P=0.05$; Table 4) but not when compared with those treated with LAMA alone (Figure S13). However, significantly more LAMA- versus LABA/LAMA-treated patients withdrew due to lack of efficacy (RR: $0.66,95 \% \mathrm{CI}$ : [0.51, 0.87], $P=0.003$; NNTH 90, 95\% CI: [56, 218]), with no such difference apparent between LABA/LAMA- and LABA/ICS-treated patients (Table 4; Figure S14).

\section{Discussion}

In this meta-analysis of 23 RCTs in 20,185 patients with stable moderate-to-very severe COPD, we compared the efficacy and safety of dual bronchodilation with four

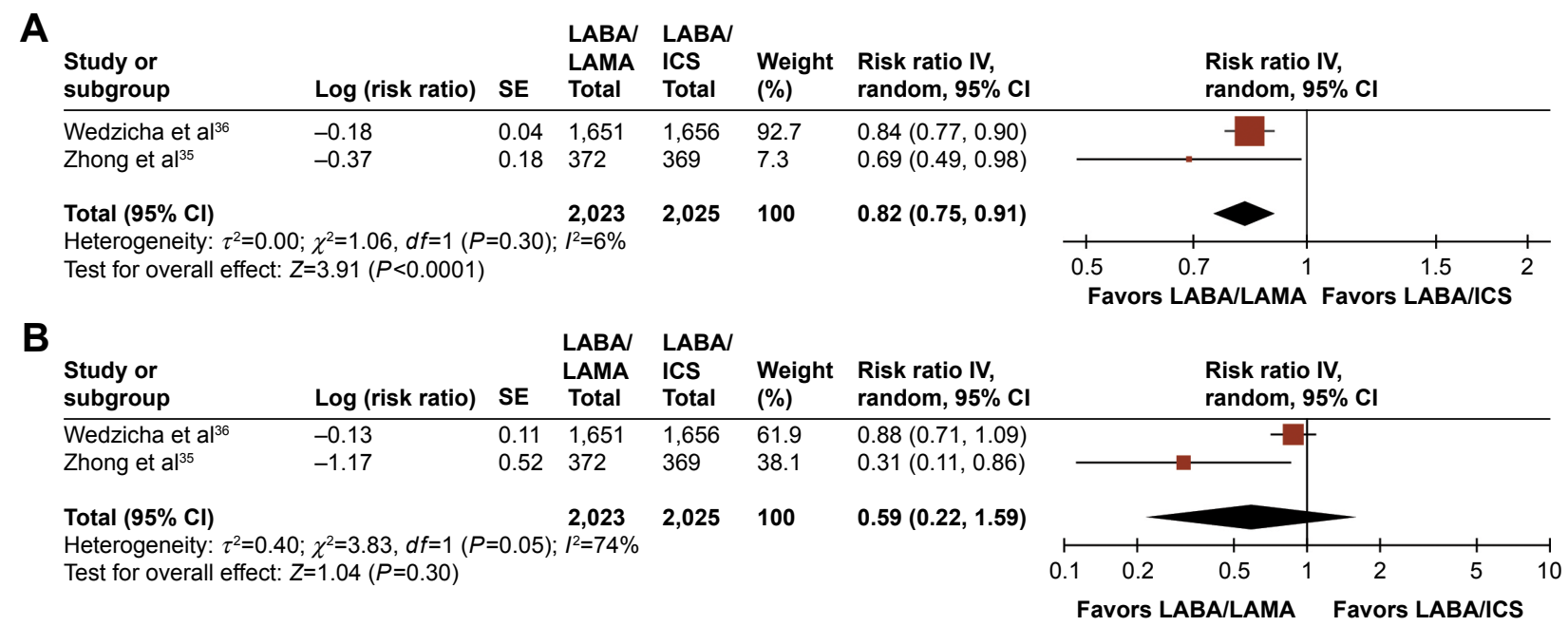

Figure 4 Pooled relative risk of annualized rates of (A) moderate and/or severe exacerbations or (B) severe exacerbations, with $95 \%$ Cls, for eligible studies comparing approved LABA/LAMA combinations with approved LABA/ICS combinations.

Note: Insufficient data prevented a similar analysis to be conducted versus approved LAMAs.

Abbreviations: $\mathrm{Cl}$, confidence interval; ICS, inhaled corticosteroid; FEV , forced expiratory volume in I second; LABA, long-acting $\beta_{2}$-agonist; LAMA, long-acting muscarinic antagonist. 
Table 4 Effect of LABA/LAMA versus LAMA or LABA/ICS on safety outcomes

\begin{tabular}{|c|c|c|c|c|c|}
\hline \multirow[t]{2}{*}{ Outcome measure } & \multirow{2}{*}{$\begin{array}{l}\text { Studies } \\
\text { included }\end{array}$} & \multicolumn{2}{|l|}{ No of patients } & \multicolumn{2}{|l|}{ Relative risk } \\
\hline & & LABA/LAMA & Comparator & Effect $(95 \% \mathrm{Cl})$ & $I^{2}, \%$ (P-value) \\
\hline \multicolumn{6}{|l|}{ Any AE } \\
\hline LABA/LAMA versus LAMA & $7,15,24-33$ & 5,687 & 6,840 & $1.00(0.98,1.02)$ & $0(0.95)$ \\
\hline \multirow[t]{2}{*}{ LABA/LAMA versus $L A B A / I C S$} & $34-39$ & 3,835 & 3,838 & $0.94(0.89,0.99)$ & $23(0.02)$ \\
\hline & & & & NNTH: $32(18,100)$ & \\
\hline \multicolumn{6}{|l|}{ Serious AEs } \\
\hline LABA/LAMA versus LAMA & $7,15,24-33$ & 5,687 & 6,840 & $1.01(0.88,1.15)$ & $21(0.94)$ \\
\hline LABA/LAMA versus $L A B A / I C S$ & $34-39$ & 3,616 & 3,656 & $0.90(0.74,1.10)$ & $18(0.32)$ \\
\hline \multicolumn{6}{|l|}{ Pneumonia } \\
\hline LABA/LAMA versus LAMA & $7,24-27,29-32,36$ & 4,439 & 5,584 & $1.04(0.78,1.38)$ & $0(0.79)$ \\
\hline \multirow[t]{2}{*}{ LABA/LAMA versus LABA/ICS } & $34-39$ & 3,835 & 3,838 & $0.59(0.43,0.8 \mathrm{I})$ & $0(0.001)$ \\
\hline & & & & NNTH: $84(54,184)$ & \\
\hline \multicolumn{6}{|l|}{ Cardiac/cardiovascular disorders } \\
\hline LABA/LAMA versus LAMA & $24-31$ & 3,533 & 4,679 & $1.09(0.77,1.55)$ & $32(0.62)$ \\
\hline LABA/LAMA versus LABA/ICS & $34-39$ & 3,835 & 3,838 & $1.17(0.78,1.76)$ & $0(0.45)$ \\
\hline \multicolumn{6}{|l|}{ Deaths } \\
\hline LABA/LAMA versus LAMA & $7,15,24-32$ & 5,282 & 6,434 & $-0.00(-0.00,0.00)$ & $0(0.46)$ \\
\hline LABA/LAMA versus LABA/ICS & $34-39$ & 3,835 & 3,838 & $0.00(-0.00,0.00)$ & $0(0.65)$ \\
\hline \multicolumn{6}{|l|}{ Withdrawals due to AEs } \\
\hline LABA/LAMA versus LAMA & $7,15,24-26,28-33$ & 5,300 & 6,448 & $0.97(0.80,1.18)$ & $19(0.78)$ \\
\hline \multirow[t]{2}{*}{ LABA/LAMA versus LABA/ICS } & $34-39$ & 3,836 & 3,841 & $0.83(0.69,0.99)$ & $0(0.04)$ \\
\hline & & & & NNTH: $88(45,1,228)$ & \\
\hline \multicolumn{6}{|l|}{ Withdrawals due to lack of efficacy } \\
\hline \multirow[t]{2}{*}{ LABA/LAMA versus LAMA } & $15,25,26,28-33$ & 3,947 & 5,173 & $0.66(0.5 \mathrm{I}, 0.87)$ & $0(0.003)$ \\
\hline & & & & NNTH: $90(56,218)$ & \\
\hline LABA/LAMA versus LABA/ICS & $34-38$ & 1,691 & 1,695 & $1.10(0.60,2.03)$ & $0(0.75)$ \\
\hline
\end{tabular}

Abbreviations: AE, adverse event; $\mathrm{Cl}$, confidence interval; NNTH, number needed to treat for harm; ICS, inhaled corticosteroid; LABA, long-acting $\beta_{2}$-agonist; LAMA, longacting muscarinic antagonist.

approved LABA/LAMA FDCs (Ind/Gly, Umec/Vi, Acli/For and Tio/Olo) with treatment using LAMA or LABA/ICS. We have shown that LABA/LAMA combinations provided superior efficacy and comparable safety profiles compared with either LAMA or LABA/ICS treatment.

The efficacy and safety of LABA/LAMA combinations has been evaluated in previous meta-analyses. ${ }^{13,14,40}$ Single LABA/LAMA combinations have been evaluated in two studies, ${ }^{13,14}$ whereas in a recent meta-analysis, ${ }^{40}$ all doses of LABA/LAMA combinations were pooled and treatment effects were compared with the combined pooled effect of the monocomponents (LABA or LAMA) and not with LABA/ ICS combinations. In our analysis, we also pooled the data from trials using the same treatments and dose regimens to facilitate comparisons between treatment subgroups. Pooling of data in this manner is recommended in meta-analyses in which there are only a few studies per subgroup because estimates within subgroups are likely to be imprecise; in such instances, the increased accuracy obtained using pooled estimates is likely to exceed any real differences between groups in the true value. The difference in our analysis compared with previous analyses is that we included all currently available LABA/LAMA combinations and chose only approved doses of these combinations and their comparators. Including all available LABA/LAMA combinations also allowed us to provide indirect insights on the potential relative efficacy of these drugs (although we also recognize that any conclusions drawn will need to be confirmed in prospective, head-to-head studies). In addition, we used as comparators the treatments most commonly prescribed in COPD clinical practice (ie, LAMAs or LABA/ICS). Finally, we elected to implement the robust methodology of a standard meta-analysis design that involved a direct, pooled analysis of LABA/LAMA with their comparators. Based on all of the above, we believe that our analysis provides clinically relevant, high-quality evidence that is applicable to daily clinical practice.

After 12 weeks of treatment, significant improvements in lung function (trough and peak $\mathrm{FEV}_{1}$ ) were observed with LABA/LAMA combinations compared with the results with LAMA or LABA/ICS. Furthermore, the percentage of LABA/ LAMA-treated patients achieving MCIDs in trough FEV was significantly higher than that with LAMA or LABA/ICS, with NNTBs of 8 and 6 , respectively. These magnitudes of 
treatment effects and NNTBs are similar to those of previous meta-analyses comparing LABA/LAMA with LAMA and/or LABA/ICS ${ }^{10,14}$ and were maintained versus both comparators after longer periods of treatments (24-26 weeks or 52 weeks). Significant improvements in peak $\mathrm{FEV}_{1}$ relative to baseline measurements were also observed at week 12 for LABA/ LAMA treatment versus both comparators (mean differences of 0.1-0.2 L). As with trough $\mathrm{FEV}_{1}$, these improvements were still evident after several weeks of treatment.

Previous analyses have shown that improvements in $\mathrm{FEV}_{1}$ are likely to be associated with improvements in patient-reported outcomes in COPD patients. ${ }^{41}$ In our analysis, LABA/ LAMA versus LAMA alone improved the patient-reported outcomes of dyspnea (TDI) and HRQoL (SGRQ) at week

A

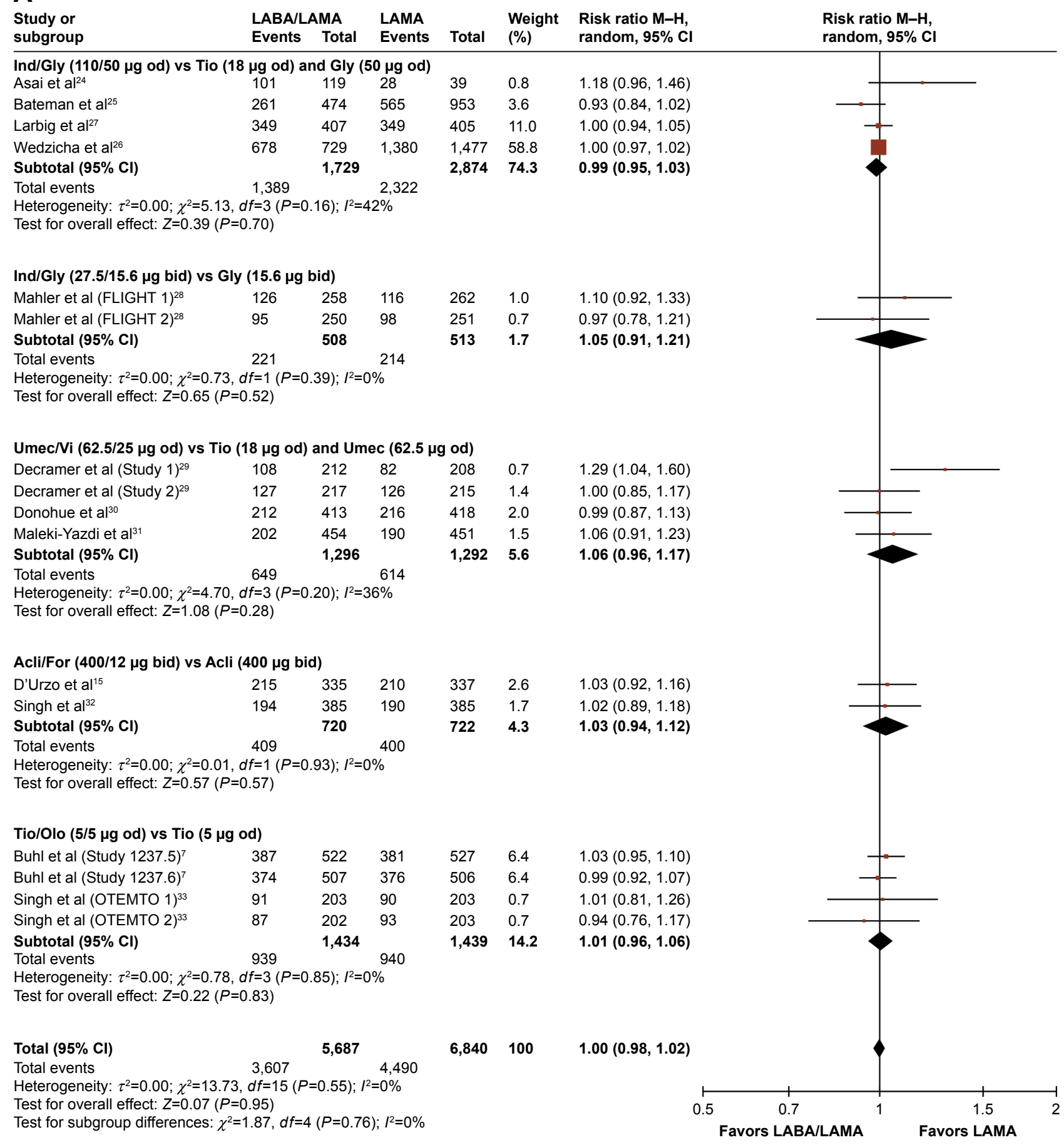

Figure 5 (Continued) 
B

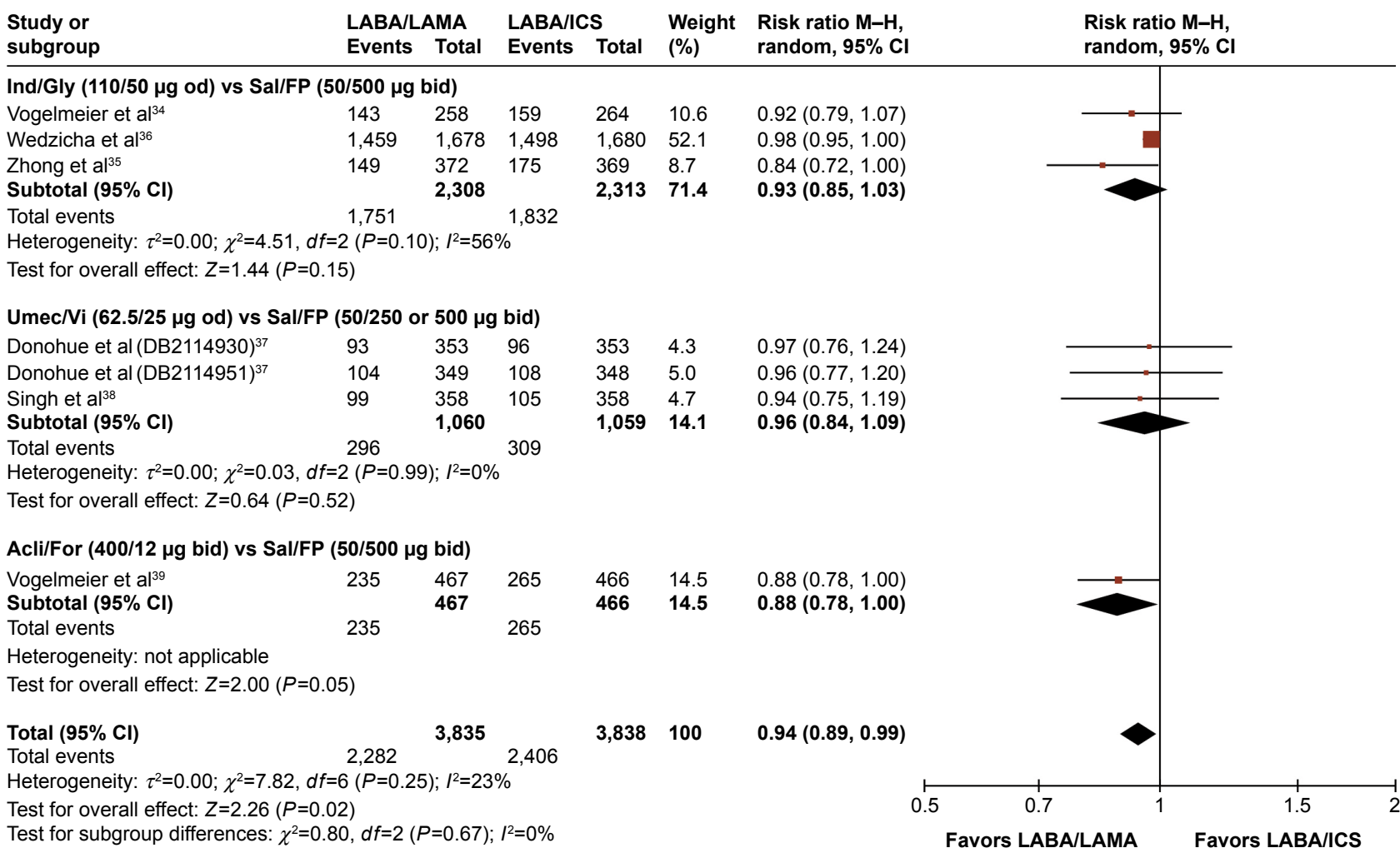

Figure 5 Pooled relative risk of AE incidence at end of treatment, with $95 \%$ Cls, for eligible studies comparing approved doses of LABA/LAMAs with approved doses of (A) LAMAs and (B) LABA/ICS combinations.

Abbreviations: AE, adverse event; Cl, confidence interval; ICS, inhaled corticosteroid; LABA, long-acting $\beta_{2}$-agonist; LAMA, long-acting muscarinic antagonist; $\mathrm{M}-\mathrm{H}$, Mantel-Haenszel test.

$12 ; 28 \%$ and $14 \%$ of LABA/LAMA- versus LAMA-treated patients, respectively, were also more likely to achieve MCIDs in these outcome measures (NNTB: 26 and 16, respectively). LABA/LAMA-treated patients also had significantly reduced requirements for rescue medications during the trial than both LAMA- and LABA/ICS-treated patients. A trend in favor of LABA/LAMA versus LABA/ICS treatment was also observed with respect to TDI score and, for health status, a significant benefit in favor of LABA/LAMA was observed at week 26 but not at week 12 versus LABA/ ICS. These differences were mainly driven by the Ind/Gly trials; however, significant heterogeneity in component studies prevented firm conclusions to be drawn. As mentioned previously, LABAs improve symptoms and HRQoL more effectively than LAMAs, while LAMAs are superior to LABAs in reducing exacerbations. ${ }^{9,11}$ Given that the severity and frequency of exacerbations are associated with impaired HRQoL, ${ }^{42}$ the improvements in HRQoL with LABA/LAMA versus LABA/ICS were more evident in studies including patients with more severe exacerbations. ${ }^{36}$

A protocol-defined end point of this meta-analysis was to examine the annualized rate of COPD exacerbations prospectively collected as an efficacy end point. Only three studies (two LABA/LAMA versus LABA/ICS comparisons $^{35,36}$ and one LABA/LAMA versus LAMA comparison $^{26}$ ) prospectively collected exacerbation rates, and therefore a meta-analysis of LABA/LAMA versus LAMA was not possible. Nevertheless, a positive signal for LABA/LAMA versus LAMA treatment was evident in the SPARK study, ${ }^{26}$ and the inclusion of data from ongoing studies such as DYNAGITO (Tio/Olo versus Tio) will clarify the role of LABA/LAMA versus LAMA treatment in the prevention of COPD exacerbations, especially in high-risk populations. Compared with LABA/ICS, however, LABA/ LAMA treatment significantly reduced the rate of moderate and/or severe exacerbations, and a trend in favor of LABA/ LAMA was also observed for reducing severe exacerbations. Whether this finding represents an effect of Ind/Gly, which was the comparator LABA/LAMA used in the two evaluated studies, ${ }^{35,36}$ or an overall effect of the LABA/LAMA class needs to be defined in prospective studies using the other available combinations.

AE incidence was significantly lower in LABA/LAMAversus LABA/ICS-treated patients $(\mathrm{NNTH}=32)$, with the 


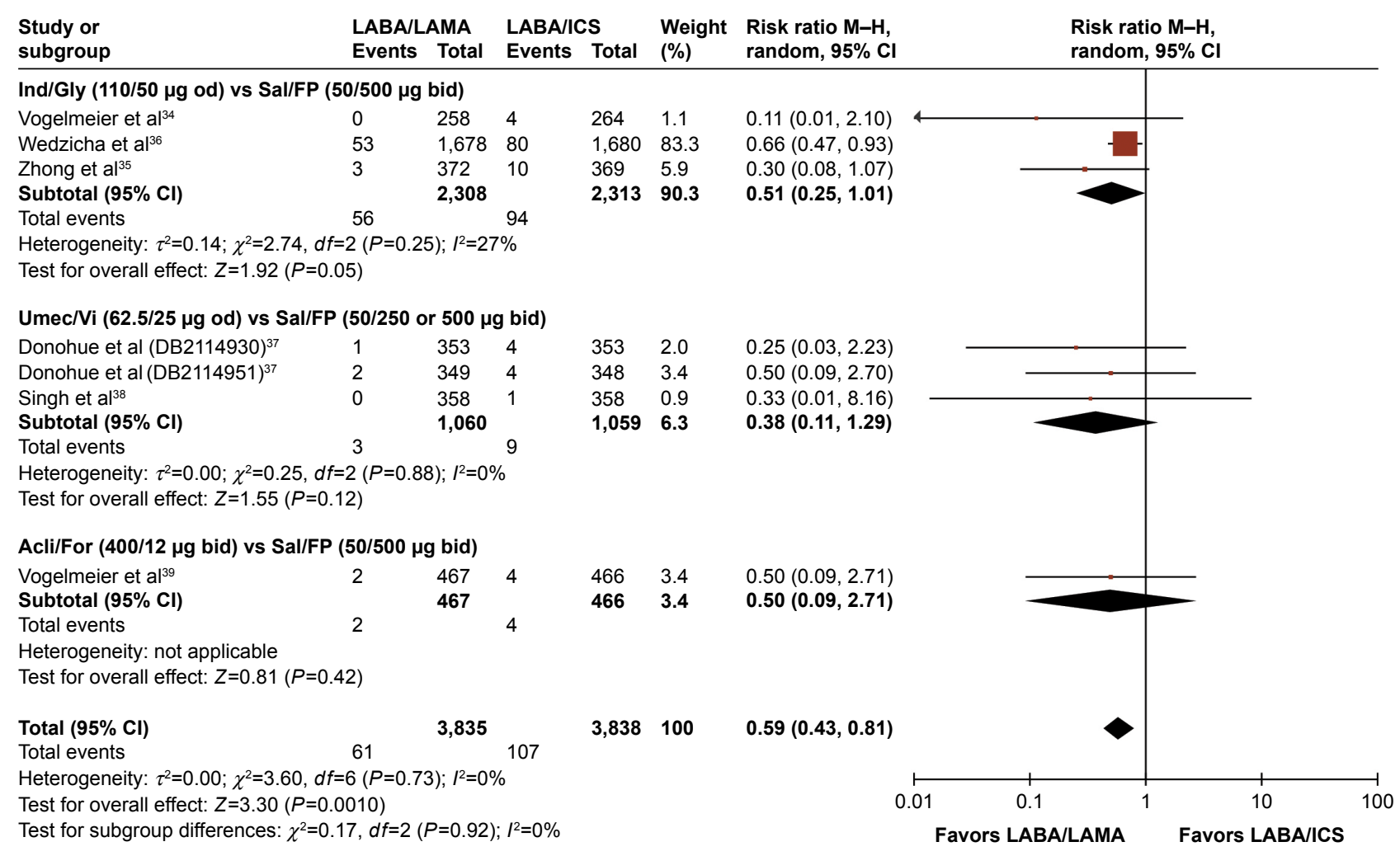

Figure 6 Pooled relative risk of pneumonia incidence, with $95 \% \mathrm{Cls}$, for eligible studies comparing approved doses of LABA/LAMAs with approved doses of LABA/ICS combinations.

Abbreviations: $\mathrm{Cl}$, confidence interval; ICS, inhaled corticosteroid; LABA, long-acting $\beta_{2}$-agonist; LAMA, long-acting muscarinic antagonist; M-H, Mantel-Haenszel test.

excess in the LABA/ICS arm plausibly related to the ICS component. This difference, however, did not translate through to SAEs, with no significant differences in SAE incidence observed between LABA/LAMA- and either LABA/ICS- or LAMA-treated patients. The incidence of pneumonia, however, was significantly lower in the LABA/LAMA group versus the LABA/ICS-treated patients (RR: 0.34). Several studies and systematic reviews comparing pneumonia risk in patients receiving ICS alone or in combination with LABA have reported a greater incidence of pneumonia in the LABA/ICS or ICS arms relative to the LABA arm. ${ }^{5,43}$ Regarding potential differences between different ICS treatments, some evidence of a higher risk of any pneumonia event has been reported with fluticasone versus budesonide, but no significant differences between the two drugs were observed in terms of SAEs (either pneumoniarelated or all-cause) or mortality. ${ }^{44}$ In the studies included in the current analysis, salmeterol/fluticasone propionate was the only LABA/ICS used as a comparator; therefore, in our systematic review, we were not able to provide additional data in this regard.

Cardiovascular events were also of particular interest as single-agent LABAs have been associated with increased risk of arrhythmias, ${ }^{45}$ whereas retrospective analyses of LABA/ ICS studies have shown a potential benefit for LABA/ICS on the risk of cardiovascular AEs versus placebo. ${ }^{46} \mathrm{~A}$ recent study demonstrated that LABA/ICS did not reduce mortality versus $\mathrm{LABA}$ /placebo in patients with, or at risk of, cardiovascular events ${ }^{47}$ disputing the notion that ICS-induced decreases in systemic inflammation can reduce mortality. In the current analysis, no significant differences were observed between any of the treatment classes with respect to cardiac or cardiovascular disorders; this is in accordance with a pooled analysis of safety data showing no increase in the risk of major cardiovascular events in COPD patients treated with LABA/LAMA (Ind/Gly) versus placebo (RR: 1.04, 95\% CI: $[0.45,2.42])^{48}$

Withdrawals due to AEs were significantly higher in LABA/ICS-treated patients compared with LABA/LAMAtreated patients, presumably due to AEs of pneumonia or other respiratory or extrapulmonary events associated with ICS use. Indeed, a significantly higher incidence of pneumonia $(P=0.02)$ was observed in the LABA/ICS arm of one of the composite studies included in this meta-analysis, while a threefold higher incidence was reported in other studies. ${ }^{35,36}$ Withdrawals due to lack of efficacy, however, occurred in 
significantly more LAMA- versus LABA/LAMA-treated patients, a finding that was driven largely by two of the component trials. ${ }^{26,31}$

There are certain potential limitations in the current analysis. 1) Open-label tiotropium was used as comparator in some studies; ${ }^{24,26}$ this may have affected patient-reported outcomes (TDI and SGRQ), although it should not bias objective outcomes such as $\mathrm{FEV}_{1}$. 2) As our sample was largely composed of patients with stable COPD and infrequent exacerbations, our findings cannot readily be applied to all patients with frequent exacerbations; nevertheless, a significant proportion of patients with frequent exacerbations were included in the two studies that evaluated exacerbations as an outcome. ${ }^{26,36} 3$ ) In this analysis, we do not provide any comparisons of LABA/LAMA versus LABA, as we wanted to evaluate the available evidence compared with the most commonly prescribed medications for COPD, namely, LABA/ICS or LAMA. That said, however, the recent network meta-analysis by Oba and Lone ${ }^{16}$ did include this comparison, finding LABA/LAMA combinations to be associated with significantly improved efficacy outcomes versus LABAs while maintaining similar safety profiles. 4) Based on the design of the studies identified for this systematic review, we are unable to provide data on outcomes beyond 52/64 weeks or on mortality or disease progression. Further studies using LABA/LAMA combinations are required to address these important scientific questions. 5) Given the heterogeneity of COPD, it would have been of interest to evaluate further parameters such as additional spirometric measures (eg, forced vital capacity [FVC] $]^{49}$ or other markers of small airways dysfunction) or the effects of treatments on physical activity. ${ }^{50,51}$ Data on such parameters are, however, not uniformly presented in RCTs; therefore, in this meta-analysis, the most commonly used clinically relevant outcomes were prespecified as the outcomes of interest. 6) Definitive conclusions on the relative efficacy of different treatments within the LABA/LAMA class cannot be made as the individual treatments were not compared head to head. Nevertheless, we observed differences between different drugs, and the clinical significance of these differences needs to be further evaluated.

\section{Conclusion}

This meta-analysis of $23 \mathrm{RCT}$ s provides evidence that LABA/ LAMA FDCs offer superior efficacy and comparable safety to LAMA or LABA/ICS in patients with stable moderateto-very severe COPD, indicating their potential as first-line treatment options for this population of patients.

\section{Acknowledgments}

The meta-analysis work was performed by Guruprasad Rao KS and Sharanbasappa Durg of Molecular Connections (P) Ltd, Bangalore, India, under the guidance of the manuscript authors and Novartis Pharma AG (Basel, Switzerland). Medical writing assistance was provided by Colette O’Sullivan, PhD, of Scriva Medical Communications Ltd, a professional medical writer funded by Novartis. Development of the manuscript was supported by Novartis Pharma AG (Basel, Switzerland). The authors received no compensation related to the development of the manuscript.

\section{Author contributions}

All authors contributed toward data analysis, drafting and critically revising the paper and agree to be accountable for all aspects of the work.

\section{Disclosure}

GJR has participated as a lecturer, speaker and advisor in scientific meetings and courses under the sponsorship of Air Products and Chemicals Inc, Almirall, AstraZeneca, Boehringer Ingelheim, Laboratorios Dr Esteve, GlaxoSmithKline, Merck Sharp \& Dome and Novartis. DP has board membership with Aerocrine, Amgen, AstraZeneca, Boehringer Ingelheim, Chiesi, Meda, Mundipharma, Napp, Novartis, and Teva Pharmaceuticals; consultancy agreements with Almirall, Amgen, AstraZeneca, Boehringer Ingelheim, Chiesi, GlaxoSmithKline, Meda, Mundipharma, Napp, Novartis, Pfizer, Teva Pharmaceuticals, and Theravance; grants and unrestricted funding for investigator-initiated studies (conducted through Observational and Pragmatic Research Institute Pte Ltd) from Aerocrine, AKL Ltd, AstraZeneca, Boehringer Ingelheim, British Lung Foundation, Chiesi, Meda, Mundipharma, Napp, Novartis, Pfizer, Respiratory Effectiveness Group, Takeda, Teva Pharmaceuticals, Theravance, UK National Health Service, Zentiva; payment for lectures/ speaking engagements from Almirall, AstraZeneca, Boehringer Ingelheim, Chiesi, Cipla, GlaxoSmithKline, Kyorin, Meda, Merck, Mundipharma, Novartis, Pfizer, Skyepharma, Takeda, and Teva Pharmaceuticals; payment for manuscript preparation from Mundipharma and Teva Pharmaceuticals; payment for the development of educational materials from Mundipharma and Novartis; payment for travel/accommodation/meeting expenses from Aerocrine, AstraZeneca, Boehringer Ingelheim, Mundipharma, Napp, Novartis, and Teva Pharmaceuticals; funding for patient enrolment or completion of research from Chiesi, Novartis, Teva Pharmaceuticals, and Zentiva; stock/stock options from AKL Ltd which produces 
phytopharmaceuticals; owns $74 \%$ of the social enterprise Optimum Patient Care Ltd, UK and $74 \%$ of Observational and Pragmatic Research Institute Pte Ltd, Singapore; and is peer reviewer for grant committees of the Efficacy and Mechanism Evaluation programme, HTA, and Medical Research Council. AA has acted as a Consultant and has served on advisory boards for Novartis Pharma AG, AstraZeneca, Boehringer Ingelheim, GlaxoSmithKline and Sunnovion. DS has received sponsorship to attend international meetings, honoraria for lecturing or attending advisory boards and research grants from various pharmaceutical companies, including Almirall, AstraZeneca, Boehringer Ingelheim, Chiesi, Genentech, GlaxoSmithKline, Glenmark, Merck, Napp, Novartis, Pfizer, Respivert, Skyepharma, Takeda, Teva, Therevance and Verona. PA, GB, FP, RF and KK are employees and shareholders of Novartis Pharma AG. KK had previously received honoraria for educational activities and lectures from AstraZeneca, Boehringer Ingelheim, Chiesi, Elpen, and Novartis, and participated on advisory boards arranged by AstraZeneca, Chiesi, Elpen, and Novartis. The authors report no other conflicts of interest in this work.

\section{References}

1. GOLD [homepage on the Internet]. From the Global Strategy for the Diagnosis, Management and Prevention of COPD, Global Initiative for Chronic Obstructive Lung Disease (GOLD); 2017. Available from: http://goldcopd.org. Accessed December 7, 2016.

2. Wedzicha JA, Decramer M, Seemungal TA. The role of bronchodilator treatment in the prevention of exacerbations of COPD. Eur Respir J. 2012;40(6):1545-1554.

3. Price D, West D, Brusselle G, et al. Management of COPD in the UK primary-care setting: an analysis of real-life prescribing patterns. Int $J$ Chron Obstruct Pulmon Dis. 2014;9:889-904.

4. Price D, Miravitlles M, Pavord I, et al. First maintenance therapy for COPD in the UK between 2009 and 2012: a retrospective database analysis. NPJ Prim Care Respir Med. 2016;26:16061.

5. Rodrigo GJ, Neffen H. A systematic review with meta-analysis of fluticasone furoate/vilanterol combination for the treatment of stable COPD. Pulm Pharmacol Ther. 2016;42:1-6.

6. Brusasco V. Reducing cholinergic constriction: the major reversible mechanism in COPD. Eur Respir Rev. 2006;15:32-36.

7. Buhl R, Maltais F, Abrahams R, et al. Tiotropium and olodaterol fixeddose combination versus mono-components in COPD (GOLD 2-4). Eur Respir J. 2015;45(4):969-979.

8. Cazzola M, Calzetta L, Page CP, et al. Pharmacological characterization of the interaction between aclidinium bromide and formoterol fumarate on human isolated bronchi. Eur J Pharmacol. 2014;745: 135-143.

9. Vogelmeier C, Hederer B, Glaab T, et al. Tiotropium versus salmeterol for the prevention of exacerbations of COPD. NEngl J Med. 2011;364(12): 1093-1103.

10. Rodrigo GJ, Neffen H. Comparison of indacaterol with tiotropium or twice-daily long-acting b-agonists for stable COPD: a systematic review. Chest. 2012;142(5):1104-1110.

11. Decramer ML, Chapman KR, Dahl R, et al; INVIGORATE investigators. Once-daily indacaterol versus tiotropium for patients with severe chronic obstructive pulmonary disease (INVIGORATE): a randomised, blinded, parallel-group study. Lancet Respir Med. 2013;1(7):524-533.
12. Cope S, Donohue JF, Jansen JP, et al. Comparative efficacy of long-acting bronchodilators for COPD: a network meta-analysis. Respir Res. 2013; 14:100.

13. Rodrigo GJ, Plaza V. Efficacy and safety of a fixed-dose combination of indacaterol and glycopyrronium for the treatment of COPD A systematic review. Chest. 2014;146(2):309-317.

14. Rodrigo GJ, Neffen $\mathrm{H}$. A systematic review of the efficacy and safety of a fixed-dose combination of umeclidinium and vilanterol for the treatment of COPD. Chest. 2015;148(2):397-407.

15. D'Urzo AD, Rennard SI, Kerwin EM, Mergel V, Leselbaum AR, Caracta CF. AUGMENT COPD study investigators. Efficacy and safety of fixed-dose combinations of aclidinium bromide/formoterol fumarate: the 24-week, randomized, placebo-controlled AUGMENT COPD study. Respir Res. 2014;14(15):123.

16. Oba Y, Lone NA. Comparative efficacy of long-acting muscarinic antagonists in preventing COPD exacerbations: a network meta-analysis and meta-regression. Ther Adv Respir Dis. 2015;9(1):3-15.

17. Liberati A, Altman DG, Tetzlaff J, et al. The PRISMA statement for reporting systematic reviews and meta-analyses of studies that evaluate health care interventions: explanation and elaboration. PLoS Med. 2009;6:e1000100.

18. Donohue JF. Minimal clinically important differences in COPD lung function. COPD. 2005;2(1):111-124.

19. Mahler DA, Witek TJ Jr. The MCID of the transition dyspnea index is a total score of one unit. COPD. 2005;2(1):99-103.

20. Jones PW. St. George's Respiratory Questionnaire: MCID. COPD. 2005; 2(1):75-79.

21. Higgins JP, Altman DG, Gøtzsche PC, et al; Cochrane Bias Methods Group; Cochrane Statistical Methods Group. The Cochrane Collaboration's tool for assessing risk of bias in randomised trials. $B M J$. 2011;343:d5928.

22. Higgins JPT, Green S. Cochrane Handbook for Systematic Reviews of Interventions Version 5.1.0; 2011 [updated March 2011]. The Cochrane Collaboration. Available from: http://training.cochrane.org/ handbook

23. Borenstein M, Hedges LV, Higgins JPT, Rothstein HR. Introduction to meta-analysis. Chichester, West Sussex: John Wiley \& Songs, Ltd; 2009.

24. Asai K, Minakata Y, Hirata K, et al. QVA149 Once-daily is safe and well tolerated and improves lung function and health status in Japanese patients with COPD: The ARISE study. Eur Respir J. 2013; 42(57):3392

25. Bateman ED, Ferguson GT, Barnes N, et al. Dual bronchodilation with QVA149 versus single bronchodilator therapy: the SHINE study. Eur Respir J. 2013;42(6):1484-1494.

26. Wedzicha JA, Decramer M, Ficker JH, et al. Analysis of chronic obstructive pulmonary disease exacerbations with the dual bronchodilator QVA149 compared with glycopyrronium and tiotropium (SPARK): a randomised, double-blind, parallel-group study. Lancet Respir Med. 2013;1(3):199-209.

27. Larbig M, Taylor AF, Maitra S, Schubert-Tennigkeit A, Banerji D. Efficacy and safety of IND/GLY (indacaterol/glycopyrronium) versus placebo and tiotropium in symptomatic patients with moderateto-severe COPD: the 52-week RADIATE study. Respirology. 2015; 20(suppl 3):A438.

28. Mahler DA, Kerwin E, Ayers T, et al. FLIGHT1 and FLIGHT2: efficacy and safety of QVA149 (indacaterol/glycopyrrolate) versus its monocomponents and placebo in patients with chronic obstructive pulmonary disease. Am J Respir Crit Care Med. 2015;192(9):1068-1079.

29. Decramer M, Anzueto A, Kerwin E, et al. Efficacy and safety of umeclidinium plus vilanterol versus tiotropium, vilanterol, or umeclidinium monotherapies over 24 weeks in patients with chronic obstructive pulmonary disease: results from two multicentre, blinded, randomised controlled trials. Lancet Respir Med. 2014;2(6):472-486.

30. Donohue JF, Maleki-Yazdi MR, Kilbride S, Mehta R, Kalberg C, Church A. Efficacy and safety of once-daily umeclidinium/vilanterol 62.5/25 mcg in COPD. Respir Med. 2013;107(10):1538-1546. 
31. Maleki-Yazdi MR, Kaelin T, Richard N, Zvarich M, Church A. Efficacy and safety of umeclidinium/vilanterol $62.5 / 25 \mathrm{mcg}$ and tiotropium $18 \mathrm{mcg}$ in chronic obstructive pulmonary disease: results of a 24-week, randomized, controlled trial. Respir Med. 2014;108(12): 1752-1760.

32. Singh D, Jones PW, Bateman ED, et al. Efficacy and safety of aclidinium bromide/formoterol fumarate fixed-dose combinations compared with individual components and placebo in patients with COPD (ACLIFORM-COPD): a multicentre, randomised study. BMC Pulm Med. 2014;14:178.

33. Singh D, Ferguson GT, Bolitschek J, et al. Tiotropium + olodaterol shows clinically meaningful improvements in quality of life. Respir Med. 2015;109(10):1312-1319.

34. Vogelmeier CF, Bateman ED, Pallante J, et al. Efficacy and safety of once-daily QVA149 compared with twice-daily salmeterol-fluticasone in patients with chronic obstructive pulmonary disease (ILLUMINATE): a randomised, double-blind, parallel group study. Lancet Respir Med. 2013;1(1):51-60.

35. Zhong N, Wang C, Zhou X, et al. LANTERN: a randomized study of QVA149 versus salmeterol/fluticasone combination in patients with COPD. Int J Chron Obstruct Pulmon Dis. 2015;10:1015-1026.

36. Wedzicha JA, Banerji D, Chapman KR, et al. Indacaterol-glycopyrronium versus salmeterol-fluticasone for COPD. NEngl J Med. 2016;374(23): 2222-2234.

37. Donohue JF, Worsley S, Zhu CQ, Hardaker L, Church A. Improvements in lung function with umeclidinium/vilanterol versus fluticasone propionate/salmeterol in patients with moderate-to-severe COPD and infrequent exacerbations. Respir Med. 2015;109(7):870-881.

38. Singh D, Worsley S, Zhu CQ, Hardaker L, Church A. Umeclidinium/ vilanterol versus fluticasone propionate/salmeterol in COPD: a randomised trial. BMC Pulm Med. 2015;15:91.

39. Vogelmeier C, Paggiaro PL, Dorca J, et al. Efficacy and safety of aclidinium/formoterol versus salmeterol/fluticasone: a phase 3 COPD study. Eur Respir J. 2016;48(4):1030-1039.

40. Calzetta L, Rogliani P, Matera MG, Cazzola M. A systematic review with meta-analysis of dual bronchodilation with LAMA/LABA for the treatment of stable chronic obstructive pulmonary disease. Chest. 2016;149(5): 1181-1196.
41. Jones PW, Donohue JF, Nedelman J, Pascoe S, Pinault G, Lassen C. Correlating changes in lung function with patient outcomes in chronic obstructive pulmonary disease: a pooled analysis. Respir Res. 2011;12:161.

42. Jones P, Miravitlles M, van der Molen T, Kulich K. Beyond FEV(1) in COPD: a review of patient-reported outcomes and their measurement. Int J Chron Obstruct Pulmon Dis. 2012;7:697-709.

43. Dransfield MT, Bourbeau J, Jones PW, et al. Once-daily inhaled fluticasone furoate and vilanterol versus vilanterol only for prevention of exacerbations of COPD: two replicate double-blind, parallel-group, randomised controlled trials. Lancet Respir Med. 2013;1(3):210-223.

44. Kew KM, Seniukovich A. Inhaled steroids and risk of pneumonia for chronic obstructive pulmonary disease. Cochrane Database Syst Rev. 2014;3:CD010115

45. Cazzola M, Matera MG, Donner CF. Inhaled beta2-adrenoceptor agonists: cardiovascular safety in patients with obstructive lung disease. Drugs. 2005;65(12):1595-1610.

46. Calverley PM, Anderson JA, Celli B, et al. Cardiovascular events in patients with COPD: TORCH study results. Thorax. 2010;65(8):719-725.

47. Vestbo J, Anderson JA, Brook RD, et al. Fluticasone furoate and vilanterol and survival in chronic obstructive pulmonary disease with heightened cardiovascular risk (SUMMIT): a double-blind randomised controlled trial. Lancet. 2016;387(10030):1817-1826.

48. Wedzicha JA, Dahl R, Buhl R, et al. Pooled safety analysis of the fixeddose combination of indacaterol and glycopyrronium (QVA149), its monocomponents, and tiotropium versus placebo in COPD patients. Respir Med. 2014;108(10):1498-1507.

49. Quanjer PH, Ruppel GL, Langhammer A, et al. Bronchodilator response in FVC is larger and more relevant than in FEV1 in severe airflow obstruction. Chest. Epub 2016 Dec 28.

50. Beeh KM, Korn S, Beier J, et al. Effect of QVA149 on lung volumes and exercise tolerance in COPD patients: the BRIGHT study. Respir Med. 2014;108(4):584-592.

51. Beeh KM, Derom E, Echave-Sustaeta J, et al. The lung function profile of once-daily tiotropium and olodaterol via $\operatorname{Respimat}((\mathrm{R}))$ is superior to that of twice-daily salmeterol and fluticasone propionate via Accuhaler((R)) (ENERGITO((R)) study). Int J Chron Obstruct Pulmon Dis. 2016;11:193-205.
International Journal of COPD

\section{Publish your work in this journal}

The International Journal of COPD is an international, peer-reviewed journal of therapeutics and pharmacology focusing on concise rapid reporting of clinical studies and reviews in COPD. Special focus is given to the pathophysiological processes underlying the disease, intervention programs, patient focused education, and self management protocols.

\section{Dovepress}

This journal is indexed on PubMed Central, MedLine and CAS. The manuscript management system is completely online and includes a very quick and fair peer-review system, which is all easy to use. Visit http://www.dovepress.com/testimonials.php to read real quotes from published authors. 